\title{
OS CONTEXTOS E OS CONTRASTES DA EDUCAÇÃO BRASILEIRA: A EDUCAÇÃO POPULAR E AS DEMANDAS POR UMA EDUCAÇÃO DE QUALIDADE
}

\author{
Fábio Mariano da Paz ${ }^{1}$, Yoshie Ussami Ferrari Leite ${ }^{2}$ \\ ${ }^{1}$ Doutorando pelo Programa de Pós-Graduação em Educação da Faculdade de Ciências e Tecnologia, UNESP - Presidente Prudente
} - SP. ${ }^{2}$ Programa de Pós-Graduação em Educação - FCT - UNESP - Presidente Prudente - SP

\section{RESUMO}

Este texto, ancorado numa abordagem qualitativa, tem por objetivo colocar em discussão os significados que são atribuídos à crise da escola pública brasileira e aos crescentes discursos a respeito da perda de sua qualidade. Para isto, elenca as principais transformações históricas e sociais pelas quais o país passou, desde o período colonial até o presente, para ressaltar que a massificação da instituição escolar, embora seja constantemente culpada pelo enfraquecimento do ensino, representa atualmente a legitimação de um novo momento histórico, no qual a população conquista de forma nunca vista no decurso da história, um de seus principais direitos sociais. Aborda ainda, os impactos das transformações ocasionadas pela expansão do ensino e as diversas perspectivas que podem ser aplicadas à análise dos padrões de qualidade da atualidade, assim como as novas responsabilidades assumidas pela escola pública para dar conta das necessidades e privações sociais acumuladas ao longo de séculos pela ausência de um Estado atuante.

Palavras-chave: Democratização do Ensino. Escola pública. Qualidade da Educação.

\section{THE CONTEXT OF EDUCATION AND THE BRAZILIAN CONTRASTS: POPULAR EDUCATION AND THE DEMANDS FOR QUALITY EDUCATION}

\begin{abstract}
This text anchored on a qualitative approach, aims to put in discussion the meanings that are attributed to the Brazilian public school crisis and the growing discourse about the loss of quality. For this, lists the major historical and social transformations through which the country passed from the colonial period to the present, to emphasize that the massification of the school, although it is constantly blamed for the weakening of teaching, currently represents the legitimacy of a new time history, in which the population of achievement like never before in the course of history, one of its main social rights. Also addresses the impacts of the changes caused by the expansion of education and the different perspectives that can be applied to the analysis of the quality standards of today, as well as new responsibilities assumed by the public school to account for the needs and social deprivation accumulated over centuries by the absence of an active state. Keywords: Democratisation of Education. Public school. Quality of Education.
\end{abstract}




\section{INTRODUÇÃO}

De modo geral, depois de séculos de exclusão social, no final do século XX a educação passou a ser expandida para outras camadas da população, gerando a democratização do ensino público, em especial, com a regulamentação e reconhecimento da gratuidade e obrigatoriedade do ensino fundamental. Ao passo que as classes populares tiveram seu direito à educação garantido, discussões de diversos âmbitos entraram em voga no cenário nacional com relação à preocupante queda da qualidade da educação. Nesse vértice, o objetivo deste texto é abordar as diferentes perspectivas a respeito dessa qualidade e do que tem sido chamado de 'crise da escola'.

Em meio a diferentes percepções a respeito de tais conceitos, busca-se refletir sobre as diversas transformações sociais e fenômenos extraescolares que podem caracterizá-los como problemas não exclusivos nem da escola, nem do âmbito nacional, mas que ocorrem, também, em diferentes países do mundo, resultantes do crescente processo de globalização, modernização das sociedades pela adoção de novos padrões econômicos e pelo enfraquecimento do papel da família e demais instituições socializadoras.

Embora sejam apontadas duas posições antagônicas para se discutir os novos padrões de qualidade da educação, procura-se evidenciar à luz da concepção civil democrática que os discursos a respeito da deterioração da escola pública elementar estão associados à hegemonia da perspectiva produtivista. Esta posição, que procura obscurecer todas as demais faces da questão, culpabiliza e internaliza na instituição escolar as origens da suposta 'crise da escola' e reduz a complexidade dos processos educativos à obtenção de resultados por meio de testes em larga escala, algo que este estudo busca desconstruir com base nos dados históricos e estudos de diversos autores.

Para dar conta dessas análises, o texto está dividido em duas partes. $\mathrm{Na}$ primeira, pretende-se investigar por meio da recorrência à história da educação, as origens da instrução popular e os processos sociais, econômicos e legais que deram sustentação à democratização do acesso ao ensino público. Entra em questão, nessa discussão, a precariedade com que ocorreu a expansão quantitativa de vagas e de alunos e a consequente luta dos trabalhadores $e$ educadores até a assunção da educação como direito público subjetivo.

$\mathrm{Na}$ segunda parte do texto, fazendo uso de relevantes reflexões desenvolvidas por alguns autores, busca-se abordar com mais profundidade a 'crise da escola' e os novos padrões utilizados para a aferição da qualidade da educação, perpassando, também, as avaliações externas da Educação Básica implantadas no Brasil de 1990 a 2010 e a urgência em valorizar alunos e docentes para a construção de novos caminhos para uma escola de qualidade. Ainda, nesse contexto, enfatiza-se a constatação da necessidade de mudança nas práticas inclusivas e pedagógicas da educação escolar do presente.

\section{Percursos da Educação Pública no Brasil: Origens da Educação Popular}

Discutir a educação como direito público subjetivo, obtido após séculos de exclusão educacional a que foi submetida a maioria da população brasileira, implica analisar como esse direito originou-se e como ele tem sido valorizado nos diferentes tempos e ações políticas no decorrer de uma história de mais de quinhentos anos. Todo o sentido dessa análise só pode ser compreendido de maneira ampla, quando se observa com freqüência nos diversos meios de 
comunicação, debates centrados na constatação de que apesar de possuir, após um longo processo histórico, uma educação pública obrigatória universalizada, esta é considerada cada vez mais de péssima qualidade.

Obviamente que os problemas educacionais não têm uma origem no seio do regime atual, eles remontam às primeiras iniciativas por ocasião da chegada dos portugueses. Neste contexto, os primeiros tempos da história do Brasil são marcados por um cenário de grande precariedade na oferta de ensino elementar. Restrito à educação promovida por intermédio dos padres jesuítas e seu interesse inicial na catequização, aos poucos o processo de escolarização voltou-se à instrução das elites, marcando o período colonial como um momento no qual, segundo Paiva (1987), a educação popular é praticamente inexistente.

Não bastasse a insuficiente atenção dada ao problema, no século XVIII, com a expulsão dos jesuítas pelo Marquês de Pombal, que desejava recolocar o Estado como definidor das políticas educacionais, uma série de inconsistências entre a tentativa legal de instituir meios de financiamento para a educação e a efetiva arrecadação dos impostos, comprometeram a manutenção das "aulas régias" ${ }^{1}$. A primeira etapa deste processo, conhecido como Reforma dos Estudos iniciou-se com o alvará de 28 de junho de 1759, que continha instruções minuciosas quanto à implementação da reforma em todo o reino.

Embora tenha sido criada a lei que regulava a cobrança do "subsídio literário" destinado ao

\footnotetext{
1 Conforme define Cardoso (2004), as Aulas Régias significavam as aulas que pertenciam ao Estado e que não pertenciam à Igreja. O sistema de ensino implantado com a Reforma dos Estudos Menores de 1759 baseava-se, portanto, nas Aulas de primeiras letras e nas Aulas de humanidades, que eram denominadas de maneira geral de Aulas Régias. Foi a Lei de 6 de novembro de 1772, que ordenou efetivamente 0 estabelecimento, nas principais cidades do país, das Aulas Régias de Primeiras Letras, de Gramática Latina e de Língua Grega, fundando novas Escolas de Estudos Menores, contudo a educação ainda não era obrigatória.
}

pagamento das "aulas régias" e à manutenção do ensino elementar e secundário, não houve evidências de que as iniciativas de instrução pública tenham ocorrido no Brasil durante o período pombalino. (DI GIORGI; LEITE;, 2010, p. 2)

Embora o poder estatal estivesse à frente e disposto a implantar reformas educacionais, a fragilidade nos pagamentos de proventos $e$ admissão dos professores também contribuíam para a formação de um contexto desfavorável e incipiente para a expansão de uma educação popular. De acordo com Cardoso (2004), o primeiro concurso para professores públicos realizado no Brasil foi em Recife, a 20 de março de 1760. Entretanto, em 1765 não havia sido nomeado nenhum professor público no Brasil, embora os concursos já houvessem se realizado. Diante desse quadro, a população brasileira recorria às aulas particulares, ou à generosidade alheia, para suprir esse aspecto da ausência do Estado.

Assim, com o acesso à educação restrito a uma parcela da população, as aulas eram dadas na casa do próprio professor, sendo que para ser professor bastava se submeter a uma prova de gramática e outra de matemática, sem exigência de formação específica ou diploma. Os professores, no alvará de 1759 receberam o privilégio de nobres, entretanto os salários, pagos em três parcelas anuais obrigou os professores a financiar o próprio ofício, haja vista a falta de apoio financeiro (CARDOSO, 2004).

É a partir da chegada da família real em 1808 que novas mudanças ocorrem visando atender aos interesses de formação acadêmica da aristocracia portuguesa e à necessidade de formação profissional, especialmente com a criação de cursos superiores como "Medicina, Agricultura, Economia Política, Química e Botânica, além de academias militares [...]" (PAIVA, 1987, p. 60). 
No âmbito da educação popular, é a partir do Império que a legislação educacional tem seu início na Constituição de 1824, que continha um artigo sobre educação escolar gratuita reservada exclusivamente aos considerados cidadãos, entretanto, continuou relegada à segundo plano, tendo em vista que as condições do país enquanto economia agrária, conferiam um caráter dispensável à instrução popular.

Di Giorgi e Leite (2010) sinalizam que até mesmo a primeira Lei Geral da Educação, de 15 de outubro de 1827, que tornava obrigatória a instalação de escolas de primeiras letras em todas as cidades, vilas e lugares mais populosos do Império brasileiro não se concretizou. Contudo, embora isto tenha ocorrido, explicitam que foi graças a ela que algumas iniciativas provinciais foram tomadas no sentido de fundar escolas de ensino elementar no país, estímulo reforçado posteriormente pelo Ato Adicional de 1834, que incumbiu o Governo Central de cuidar da educação das elites, constituída pelas faculdades de medicina, os cursos jurídicos e academias e $o$ isentou de sua responsabilidade "em relação ao ensino elementar, atribuindo às províncias, que, carentes de recursos, pouco puderam realizar em favor da educação popular, que se desenvolveu precariamente durante todo 0 Império." (DI GIORGI; LEITE, p. 308, 2010).

Ao retratar a situação da escola na segunda metade do século XIX, Paiva (1987, p. 67) apresenta dados importantes sobre 0 atendimento educacional no período:

Com uma população de 8 milhões de habitantes livres e quase 2 milhões de escravos, $20 \%$ da população total não era automaticamente considerada para fins educacionais. Dos $80 \%$ restantes (população livre), calculou-se a população escolar em torno de $15 \%$. Ora, o que observamos através dos dados é que, no conjunto do país, não chegávamos a atender através do ensino público e privado - há um século, nem mesmo a $9 \%$ da população escolar calculada sobre os habitantes livres.

É somente a partir do desenvolvimento econômico na região centro-sul, abolição da escravatura, imigração européia e abertura de estradas de ferro para escoamento das produções agrícolas e industriais, marcadamente no final do período imperial, que a educação elementar é considerada foco de preocupações em um país em crescente transformação.

De acordo com Paiva (1987) no período que sucede a instauração da República os novos ideais democráticos já reforçavam essa preocupação, em geral por meio de pronunciamentos com apelo popular-democrático, assim como observado no parecer-projeto de Rui Barbosa de 1882, que traçou um diagnóstico da educação popular ofertada no Brasil.

Mesmo com alguns avanços na esfera social e reconhecimento de alguns segmentos da necessidade da oferta de instrução primária à população, a gratuidade do ensino que havia sido contemplada na Constituição de 1824, morre na Constituição de 1891, que se cala sobre o assunto, pois, radicalizando a autonomia dos estados, deixava essa incumbência às constituições dos mesmos. Após 1891, muitos estados assumiram a gratuidade, mas boa parte deles repassou essa incumbência aos municípios, pobres em arrecadação de impostos.

Conforme Cury (2003) a alteração no estatuto da gratuidade no ensino primário e a sua obrigatoriedade só foram postas em voga novamente na Constituição de 1934, isto porque a Carta Magna foi altamente influenciada pelas conseqüências da $1^{\text {a }}$ Guerra Mundial, Manifesto dos Pioneiros da Educação, difusão dos ideais capitalistas e exigências impostas por um contingente significativo de proletariados. Essa nova constituição, além de incumbir a União, no 
seu artigo 5ำ, inciso XIV, de traçar as diretrizes da educação nacional, também dá maior ênfase à educação como direito do cidadão. ${ }^{2}$

Paralelamente a esses acontecimentos, ocorre em 1938 a criação do Instituto Nacional de Estudos Pedagógicos (INEP), e em 1942, do Fundo Nacional do Ensino Primário, proporcionando expansões dos sistemas de ensino, principalmente a partir de 1945 graças a uma conjuntura mais favorável ao ensino elementar, com a aprovação em 1946 da Lei Orgânica do Ensino Primário.

Figura 1. A Organização da Escola em Três Momentos $^{3}$

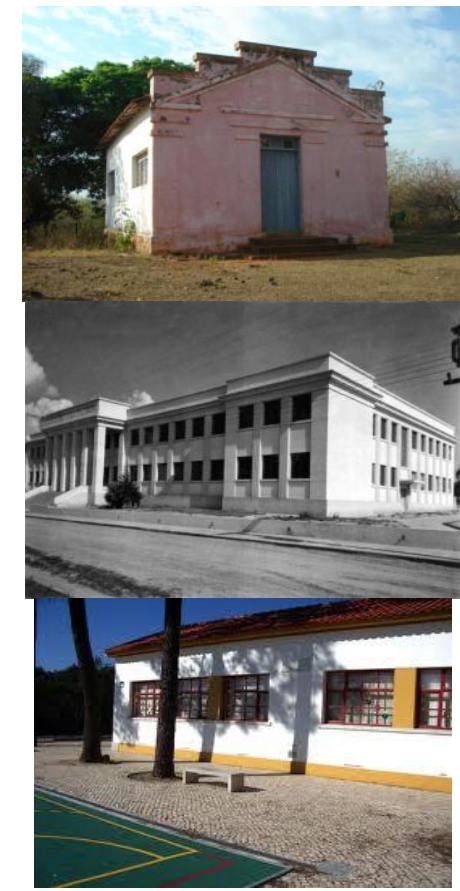

Nota 1. De cima para baixo, escola de improviso (séc. XVIII a

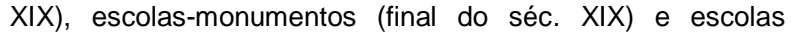
funcionais (1930 em diante)

Fonte: Faria Filho e Vidal (2000), Paz et al (2011).

\footnotetext{
${ }^{2}$ É a única constituição, antes de 1988, que reconhece ao adulto 0 acesso à escolarização como direito. E, para que, de fato, se garantisse o dever do Estado com o ensino primário gratuito e obrigatório, criou-se uma vinculação constitucional de recursos exclusivos para a Educação. Essa vinculação estará presente na Constituição de 1934, 1946 e 1988.

3 Escola de improviso e escola-monumento existentes, respectivamente, em área rural e central do município de Birigui - SP. A escola funcional representa modelo comumente encontrado nas redes municipais e estaduais do país. De acordo com Faria Filho e Vidal (2000), partiram de Anísio Teixeira, no Rio, em 1933, e Almeida Júnior, em São Paulo, em 1936, as propostas para construção de prédios escolares mais funcionais e econômicos, entretanto, a substituição de um modelo por outro ocorreu gradativamente, sem o total abandono de algumas construções dos modelos anteriores.
}

No mesmo sentido, segundo Horta (1998) a versão final da Constituição de 1946 reafirma o direito de todos à educação, a obrigatoriedade e gratuidade do ensino primário e a gratuidade do ensino oficial ulterior ao primário para quantos proverem falta ou insuficiência de recursos. Não explicita, porém, a educação como dever do Estado, nem assume o conceito amplo de obrigatoriedade. Dados históricos da época evidenciam um alto índice de exclusão dentre os que tinham acesso à instituição escolar, como se observa na Figura 2, em registro de notas e disciplinas de um grupo escolar da década de 1940.

Figura 2. Folha de Registro de Grupo Escolar da década de 1940.

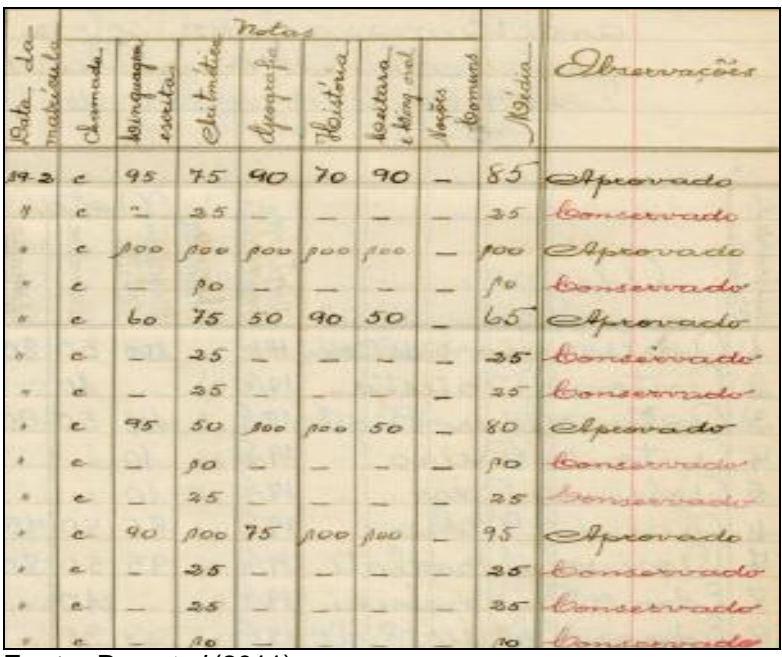

Fonte: Paz et al (2011)

É importante destacar que, neste contexto, por influência do texto constitucional de 1946, a Lei de Diretrizes e Bases, promulgada em 1961, incorpora os princípios do direito à educação, da obrigatoriedade escolar e da extensão da escolaridade obrigatória, nos seguintes termos:

Art. $2^{\circ}$ - A educação é direito de todos e será dada no lar e na escola.

Art. $3^{\circ}$ - O direito à educação é assegurado: pela obrigação do poder público e pela liberdade de iniciativa particular de ministrarem o ensino em todos 
os graus, na forma da lei em vigor;

Art. 27 - O ensino primário é obrigatório a partir dos sete anos, e só será ministrado na língua nacional. Para os que o iniciarem depois dessa idade poderão ser formadas classes especiais ou cursos supletivos correspondente ao seu nível de desenvolvimento.

Vieira e Farias (2007) apontam que a LDB, Lei no 4024/61, favoreceu mais a ideologia da escola privada do que o aprimoramento da escola pública, enquanto Di Giorgi e Leite (p. 313, 2010), registram “[...] que há apenas 49 anos o Brasil conta com uma legislação que aglutina, pela primeira vez, os diferentes níveis e modalidades de ensino em um único texto", o que leva a uma melhor compreensão da precariedade e insatisfações atuais com a qualidade do ensino público no Brasil, bem como as elevadas taxas de reprovação que persistiram ao longo de toda a história.

Durante o regime militar, a Constituição de 1967 manteve os mesmos pontos da anterior, estendendo, porém, a gratuidade e obrigatoriedade da educação dos 7 aos 14 anos. Segundo Cury (2003), um aspecto curioso é que o texto aumentou o tempo da escolaridade e retirou a vinculação constitucional de recursos com a justificativa de maior flexibilidade orçamentária. O corpo docente pagou a conta com duplo ônus: financiou a expansão com o rebaixamento de seus salários e a duplicação ou triplicação da jornada de trabalho.

Ainda nesse cenário repressivo, sem maiores debates e sem discussões nos meios acadêmicos e políticos, foi promulgada a Lei $\mathrm{n}^{\circ}$ 5.692/71, fixando diretrizes e bases para o ensino de primeiro e segundo graus, o que, a exemplo da referida constituição, trouxe o aumento de quatro para oito anos, durante a escolarização obrigatória.
No final da década de 70 e mais intensamente na primeira metade dos anos 80, deu-se a reabertura democrática, inicialmente "lenta e gradual", o que decorreu das melhorias substanciais na economia, em função do "Milagre Econômico", urbanização e industrialização do país, processos que colocaram a universalização do ensino primário e produção de mão-de-obra qualificada, como indispensáveis à ordem econômica e acesso ao campo produtivo (HORTA, 1998).

A Constituição aprovada em 1988 amplia a autonomia dos Estados e Municípios, promovendo estes à condição de entes federados. Para Di Giorgi e Leite:

[...] comparada às outras Constituições, apresenta o mais longo capítulo sobre educação. Consagra-a como direito público subjetivo e estabelece o princípio da gestão democrática do ensino público, o dever do Estado em prover creche e préescola às crianças e o ensino fundamental obrigatório e gratuito para todos. (DI GIORGI; LEITE, p. 314, 2010)

Em relação à política educacional advinda da nova Constituição, Horta (1998) afirma que a partir de 1996, um conjunto de novos dispositivos legais é aprovado com vistas a dar sustentação à universalização da educação básica. Nesse ano é aprovada a Lei de Diretrizes e Bases da Educação Nacional (LDB), Lei n 9394, que abriu caminhos para a organização dos sistemas de ensino municipais, induzindo claramente à municipalização. Em seguida é aprovada em consonância com a Emenda Constitucional no 14/1996, a Lei no 9424, também em 1996, regulamentando o Fundo de Manutenção de Desenvolvimento do Ensino Fundamental e de Valorização do Magistério, conhecido como FUNDEF. Este fundo passa a financiar o ensino fundamental através do repasse de recursos financeiros com base no número de matrículas e 
fixa que no mínimo $60 \%$ dos recursos deverão ser usados para remuneração dos professores em exercício. Prevê também a celebração de convênios entre estados e municípios, o acompanhamento da aplicação dos recursos financeiros do Fundo por meio de Conselhos nas três esferas do poder público, a formação de professores e existência de plano de carreira do magistério.

Já a Emenda no 53/06, ao instituir o FUNDEB, representou um avanço em termos da implementação progressiva do direito à educação, pois incluiu o atendimento à educação infantil e ao ensino médio entre suas metas, além de prever o fortalecimento dos conselhos de acompanhamento dos gastos públicos com a educação.

Figurando entre um dos grandes desafios à universalização da educação básica, a nova LDB dá um grande impulso para a superação das altas taxas de reprovação escolar, ao permitir o arranjo das etapas escolares em ciclos de aprendizagem. Os índices caem gradativamente entre as décadas de 1950 a 1990, como resposta a série de políticas educacionais empreendidas ao longo desse período.

Figura 3. Analfabetismo e Escolarização

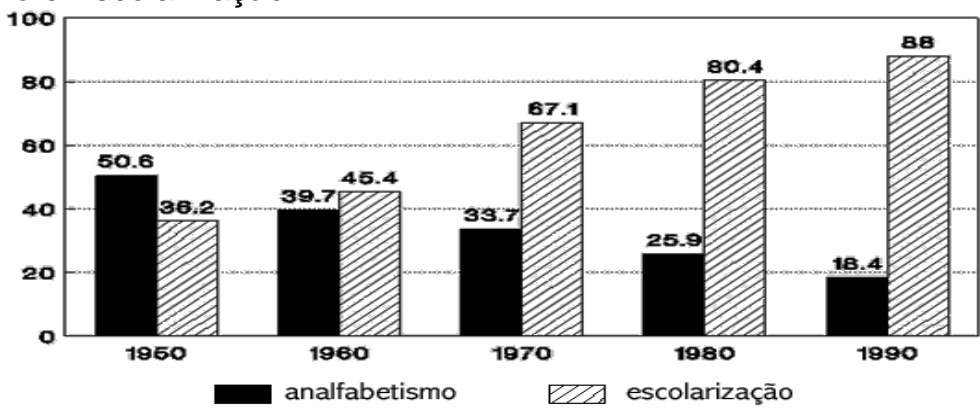

analfabetismo: \% de maiores de 5 anos escolarização: \% da faixa 7 a 14 anos

Fonte: Goldemberg (1993)

Dados mais recentes sobre a expansão do ensino público demonstram que de 1991 a 1998, a população de 7 a 14 anos com acesso à escola atingiu 95,3\%, e em 2006 este número saltou para $97,6 \%^{4}$, o que levou, segundo Beisiegel (2005), à efetiva democratização do ensino. Obviamente que isto se deu mediante a imposição de alguns mecanismos legais como a Lei o 8069/93, que estabelece o Estatuto da Criança e do Adolescente (ECA) e com o Código Penal Brasileiro, que no artigo 246, estabelece que "deixar, sem justa causa, de prover instrução

\footnotetext{
${ }^{4}$ Pesquisa Nacional por Amostras de Domicílios (PNAD 2006), realizada pelo Instituto Brasileiro de Geografia e Estatística (IBGE).
}

primária de filho em idade escolar" constitui crime de abandono intelectual, passível de pena de detenção, de quinze dias a um mês, ou de multa. Foram, também, essas medidas de responsabilização, as indutoras de considerável resultado frente às violências e práticas de exploração infantil, que impediam o acesso de muitas crianças à escolarização.

No próximo item deste estudo, analisaremos mais detidamente essas novas demandas e os problemas atribuídos à escola pública, enquanto instituição tratada por alguns segmentos como ineficiente e de pouca qualidade. 
Crise na escola pública: perspectivas para uma análise da qualidade da escola

Ao conseguir colocar, praticamente, toda a população em idade escolar dentro dos sistemas de ensino, novas demandas se apresentam como desafios educacionais, que se sobrepõem à questão de acesso quantitativo, e passam a exigir políticas de melhoria da qualidade da educação. Essas novas exigências encontram respaldo no artigo 75 da nova LDB, que atribui à União a tarefa de corrigir, progressivamente, as disparidades regionais, a fim de que se garanta um padrão mínimo de qualidade aos sistemas de ensino como um todo.

É preciso reforçar, que ao longo de mais de quinhentos anos de história, é a primeira vez que as classes populares têm acesso aos níveis mais variados da escolarização, desde a creche ao ensino superior. Juntamente com essa melhoria no acesso, outras tantas questões, como o atendimento a uma clientela diferente do aluno do passado, a ausência de condições físicas e até mesmo de professores, trazem para a escola tensões que são interpretadas pelos diversos segmentos, como uma crise da escola.

Cumpre destacar que atreladas às questões estruturais, a escola pública não tem conseguido se adequar pedagogicamente às características de sua clientela, pois continua exercendo resistência a alterações na sua estrutura organizacional conservadora e à ressignificação de sua atuação para o desenvolvimento de um processo educativo mais inclusivo e de qualidade.

No Brasil, após o alcance de índices de cobertura próximos dos $100 \%$ da população em idade escolar, a crise da escola pública - que antes era identificada como uma crise de insuficiência de oferta - passa a ser identificada com a falta (ou a perda, para os mais nostálgicos) de qualidade no seu ensino ou, dito de outra forma, da sua incapacidade de assegurar, àqueles que a frequentavam, o domínio de um elenco mínimo de conhecimentos tomados como essenciais para a inserção dos indivíduos na vida social como adultos produtivos, autônomos, ativos, participantes.

(BARROSO, 2008, p. 44)

\section{Nessa perspectiva, Barroso (2008)} esclarece que embora diversos setores da sociedade procurem tratar os novos problemas educacionais de forma bastante objetiva e evidenciável, associando-os a uma grave crise,

[...] A apontada crise dos sistemas educativos não reside em um lugar único, claramente visível, à espera de ser descrita 'tal como é'. Trata-se de uma construção, uma produção de olhares que se debruçam sobre a educação pública e elegem, no conjunto complexo sobre a qual ela está fundada, 'alvos' que expressam desejos e intenções relativos àquilo que a educação escolar não é e deveria ser. É, portanto, um campo aberto a disputas em torno de seus sentidos. (BARROSO, 2008, p. 44)

$\mathrm{Na}$ mesma direção, ao considerar que a crise da escola pode não ser restrita apenas ao seu projeto institucional e a sua cultura, a investigação sobre o significado atribuído a ela deve ser tratado como algo que extrapola suas paredes e abrange outros âmbitos da sociedade como um todo. Portanto, as tensões que enfrenta a escola representam uma crise originada ou constituída fora dos seus contextos sociais ou cognitivos internos, mas que a atingem de maneira preocupante. "É o caso dos efeitos da globalização econômica e cultural, das mudanças sensíveis nos sistemas produtivos e no papel dos Estados-Nação e, principalmente, da expansão das tecnologias da informação". (BARROSO, 2008, p. 35)

Somando-se aos elementos externos citados anteriormente, Tedesco (1998) apresenta 
uma série de transformações sociais que afetam a escola, como o enfraquecimento da hierarquia social, da sequenciadade no acesso ao conhecimento e na ressignificação da democracia e do nacionalismo. Reforça, em especial, que a própria unidade familiar está em processo de fragmentação, o que tem causado a redução de sua capacidade socializadora, resvalando ainda mais nos espaços de aprendizagem escolar:

Os professores percebem esse fenômeno cotidianamente, e uma de suas queixas mais recorrentes é que as crianças chegam à escola com um núcleo básico de socialização insuficiente para encarar com êxito a tarefa da aprendizagem. Para dizê-lo de forma muito esquemática, quando a família socializava, a escola podia ocupar-se de ensinar. Agora que a família não cumpre plenamente seu papel socializador, a escola não só não pode efetuar sua tarefa específica com a eficácia do passado, mas começa a ser objeto de novas demandas para as quais não está preparada. (TEDESCO, 1998, p. 73-74)

Assim, certamente é preciso cautela ao afirmar que a crise é somente por ineficiência e inteira responsabilidade da escola. Antes, mais conveniente e prudente seria dizer que a crise nada mais é do que reflexo das constantes mudanças em trânsito na sociedade e seus diversos segmentos, desde os relacionados aos meios de produção e difusão dos conhecimentos, quanto nos setores político, econômico e no modo de acesso aos bens de consumo e novas tecnologias.

Para Beisiegel (2005, p. 112), a crise atual, passa pelo precário financiamento estatal para a expansão dos sistemas de ensino, posto que este se deu em um contexto no qual as possibilidades de investimentos financeiros no ensino eram pequenas, e portanto "[...] o ensino cresceu em grande parte mediante a improvisação de prédios, de salas de aula; multiplicaram-se os períodos de funcionamento dos prédios existentes, improvisaram-se professores, etc."

Nesse sentido, é fundamental que se tenha consciência, ainda, de que não só a escola pública brasileira mudou, mas também a população que a frequenta. As necessidades e características dos alunos atuais não podem ser tratadas da mesma forma como se fossem as mesmas de décadas atrás. Sendo assim, é correto afirmar que nossa escola pública não tem qualidade? É sensato afirmar que sua qualidade se perdeu com a entrada desse novo alunado, proveniente das camadas populares? $\mathrm{E}$, finalmente, é a crise escolar um fenômeno nacional ou mundial? Sobre isto, Dermerval Saviani (1992, p. 10 apud SINGER, 1996, p. 13) explica que nos EUA existe uma situação igualmente preocupante, com "[...] escolas mal equipadas, drop-outs, falta de professores e um número enorme de diplomados do $2^{\circ}$ grau que continuam sem saber ler, escrever e fazer contas [...] $O$ índice de evasão relativo aos alunos que frequentam a escola secundária se aproxima dos $30 \% "$.

Desse modo, tentar discutir se uma educação é ou não de qualidade não é tarefa fácil, especialmente quando se tem em mente que a relevância deste enfoque ainda é algo subordinado a diversas perspectivas e concepções na literatura educacional. A busca de compreensão do significado da palavra "qualidade", segundo Souza, deve passar por algumas reflexões, pois:

Qualidade não é 'algo dado' não existe 'em si' remetendo à questão axiológica, ou seja, dos valores de quem produz a análise de qualidade. A emergência de critérios de avaliação não se dá de modo dissociado das posições, crenças, visão de mundo e práticas sociais de quem os 
concebe. É um conceito que nasce da perspectiva filosófica social, política de quem faz o julgamento e dela é expressão, portanto, os enfoques e critérios assumidos em um processo avaliativo revelam as opções axiológicas dos que dele participam (SOUZA, 1997, p. 267).

Logo, para se falar de qualidade da escola pública, cumpre lembrar de suas ambiguidades, afinal, se a complexidade dos fatores que levam à constatação da falta qualidade nos processos educativos ofertados à população, depende dos olhares que the são projetados, faz-se urgente distingui-los. Assim, podem-se citar duas posições antagônicas citadas por Singer (1996, p. 5): a civil democrática, que considera que a escola pública não perdeu qualidade com a democratização do acesso à educação, mas ganhou qualidade, pois se abriu à diversidade e voltou-se para a formação cidadã, e a visão produtivista, "que concebe a educação sobretudo escolar como preparação dos indivíduos para o ingresso, da melhor forma possível, na divisão social do trabalho."

O autor defende veementemente, apesar de reconhecer a esmagadora preponderância da posição produtivista na sociedade atual, a concepção civil democrática. Oliveira (2007 apud DI GIORGI; LEITE, 2010, p. 317) afirma que a qualidade, dentro da posição civil democrática, passa por três dimensões: insumos adequados a um financiamento educacional que ultrapasse as normas neoliberais e promova investimentos de acordo com as necessidades reais das escolas, processos educativos que incorporem o novo público escolar advindo da camada popular de modo a incluí-lo e, por último, resultados.

$\mathrm{Na}$ mesma direção, Oliveira e Araújo (2004) estudando a evolução do sentido da palavra "qualidade" na educação brasileira definiram três significados distintos que se aproximam das posições assinaladas por Singer (1996): um primeiro, condicionado pela oferta limitada de oportunidades de escolarização; um segundo, relacionado à idéia de fluxo, definido como número de alunos que progridem ou não dentro do sistema de ensino; e, finalmente, a ideia de qualidade associada à aferição de desempenho mediante testes em larga escala, sendo esta a que se encaixa na posição produtivista, apontada por Singer (1996).

Em relação à qualidade associada à posição produtivista, Oliveira e Araújo (2004) apontam que recentemente temos sido bombardeados por avaliações externas das mais variadas instâncias governamentais, almejando uma aferição da qualidade produzida tanto nos sistemas de ensino, bem como nas escolas. A grande ênfase situa-se nas avaliações produzidas pelo Governo Federal e Estadual, especialmente para o nível de ensino fundamental, como vemos no quadro a seguir. 
Quadro 1. Avaliações Externas da Educação Básica no Brasil (1990 a 2010).

\begin{tabular}{|c|c|c|c|}
\hline Avaliação Externa & $\begin{array}{c}\text { Órgão } \\
\text { Responsável }\end{array}$ & Público-Alvo & $\begin{array}{l}\text { Ano de } \\
\text { Criação }\end{array}$ \\
\hline SAEB & MEC/INEP & $\begin{array}{l}\text { Alunos do } 5^{\circ} \text { e } 9^{\circ} \text { anos do Ensino } \\
\text { Fundamental e } 3^{\circ} \text { ano do Ensino } \\
\text { Médio }\end{array}$ & 1988 \\
\hline ENEM & MEC/INEP & $\begin{array}{l}\text { Alunos que estão concluindo ou já } \\
\text { concluíram o ensino médio }\end{array}$ & 1998 \\
\hline PISA & OCDE & $\begin{array}{l}\text { Estudantes com } 15 \text { anos (conclusão } \\
\text { do ensino fundamental) }\end{array}$ & 2000 \\
\hline Prova Brasil & MEC/INEP & $\begin{array}{l}\text { Alunos do } 5^{\circ} \text { e } 9^{\circ} \text { ano do Ensino } \\
\text { Fundamental e } 3^{\circ} \text { ano do Ensino Médio }\end{array}$ & 2005 \\
\hline Provinha Brasil & MEC/INEP & $\begin{array}{l}\text { Alunos do } 2^{0} \text { ano } \\
\text { Fundamental }\end{array}$ & 2008 \\
\hline SARESP & SEE/SP & $\begin{array}{l}\text { Alunos do } 3^{\circ}, 5^{\circ}, 7^{\circ} \text { e } 9^{\circ} \text { anos do } \\
\text { Ensino Fundamental e } 3^{\circ} \text { ano do } \\
\text { Ensino Médio }\end{array}$ & 1996 \\
\hline
\end{tabular}

Fonte: Paz (2011)

Apesar das inúmeras avaliações que os alunos do Ensino Fundamental e Médio devem realizar em determinadas etapas da escolarização, observa-se, ainda, que os resultados gerais não tem sido satisfatórios, do ponto de vista da qualidade oficial (produtivista).

Notadamente, cada uma dessas avaliações tem trazido à tona resultados desfavoráveis à educação brasileira, entretanto, a simples divulgação de "medidas de aprendizagem", tendo como enfoque a aplicação de testes em larga escala, não tem servido para transformar essa situação. A questão da qualidade circunscrita à aplicação de avaliações externas gera um grande problema, pois "cada nova iniciativa para enfrentar os problemas educacionais costuma mencionar a criação de novos instrumentos de avaliação, como se os problemas decorressem da ausência deles". (MACHADO, 2007, p. 282)

Um outro ponto passível de análise é que a questão da qualidade, com base nas avaliações externas, traduz-se em parâmetros mensuráveis, comparativos e criação de rankings, produzindo uma competitividade dentro dos sistemas educacionais. É esta visão mercantilizadora da educação que Singer (1996) critica, quando a compara com a perspectiva de uma concepção civil democrática.

Considerando que as escolas sempre serão diferentes, em razão da diversidade de seus contextos e projetos e, recentemente, pela inserção de milhões de novos alunos, é indispensável pautar a análise da qualidade da educação superando a visão produtivista, e retornando ao pensamento de Beisiegel (2005), refletir sobre as demandas de aprendizagem pautadas na escola do passado, que em certa medida, reforçam a difusão da ideia da crise da escola pública do presente e ofuscam as grandes conquistas obtidas em relação à educação popular:

Eu não sei se essa forma de avaliar a qualidade do ensino, de pensar a redação sofisticada, no bom gosto da redação é um critério válido para se avaliar o rendimento dessa faixa da escolaridade de $1^{\circ}$ grau do presente. $O$ que eu queria colocar nessa fase da reflexão, a respeito da crítica conservadora à crise do ensino atual, é que a escola mudou, mudou radicalmente, e que a população também [...] Qualidade de ensino e conteúdos das disciplinas são pensados a partir de uma escola que já foi superada. [...] (BEISIEGEL, 2005, p. 116) 
Essa consciência a respeito da complexidade da crise da escola e sua disseminada falta de qualidade colocam-nos em condição de afirmar que visando superar a adoção de um "padrão único de qualidade", ensejada na LBD, é mais viável adotar uma perspectiva civil democrática, que permita analisar os avanços da educação tendo como ponto de partida diversos fatores, e não apenas indicadores imediatos resultantes de testes padronizados. Isto requer, portanto, que se considere, a princípio, a própria democratização do acesso à escola, como um dos fatores do aumento de sua qualidade, o que revelaria mais coerência com o caráter polissêmico desse conceito e admitiria a existência de padrões de qualidade.

Ademais, autores como Dourado e Oliveira (2009) já levantaram o debate de que discutir qualidade na educação, envolve, igualmente, a análise de sistemas e unidades escolares, bem como o processo de organização e gestão do trabalho escolar, que implica, por sua vez, outras questões como condições de trabalho, processos de gestão da escola, dinâmica curricular, formação e profissionalização docente.

Em outros termos, a qualidade da educação envolve dimensões extra e intraescolares e, nessa ótica, devem se considerar os diferentes atores, a dinâmica pedagógica, ou seja, os processos de ensinoaprendizagem, os currículos, as expectativas de aprendizagem, bem como os diferentes fatores extraescolares que interferem direta ou indiretamente nos resultados educativos. (DOURADO; OLIVEIRA, 2009, p. 205,)

Desse modo segundo o pensamento de Davok (2007), uma educação de qualidade pode significar tanto aquela que possibilita o domínio eficaz dos conteúdos previstos nos planos curriculares, como aquela que possibilita a aquisição de uma cultura científica ou literária, ou aquela que desenvolve a máxima capacidade técnica para servir ao sistema produtivo, ou, ainda, aquela que promove o espírito crítico e fortalece o compromisso para transformar a realidade social, por exemplo.

Assim, pode-se depreender que a constante disseminação de que a educação se deteriorou e está ruim hoje em dia, tem origem no inconformismo e não-aceitação de um novo sujeito histórico, que se insere numa nova escola. Entretanto, na concepção civil democrática assumida por Beisiegel (2005, p. 121) pode-se notar o ponto que o autor indica ser fundamental para superar essa situação:

[...] o problema central é esse: é possível aceitar a democratização do ensino. Quem defende a democratização do ensino não pode recusar, não pode criticar a qualidade do aluno da nossa escola. O rendimento precário da nossa escola é um dado da nossa realidade nacional. Não podemos mudar a população: não dá, a nossa população é essa. Precisamos fazer com que a escola passe a responder a essa população. Esse é o meu ponto.

Contudo, o autor explicita que fazer a escola responder a essa população não quer dizer pensar numa escola alternativa, abandonar de vez esse modelo que já não merece qualquer novo empreendimento, mas trabalhar com a escola que existe, de modo a valorizar o fato de que ela atende a grandes massas e cada vez mais se estende a um número maior de brasileiros.

O desafio que se apresenta à escola pública atual é 0 de assegurar a indissociabilidade entre 0 acesso, permanência e sucesso na escola, ressignificando a qualidade do ensino que oferece. Beisiegel (2005, p. 120) torna 
evidente que 0 primeiro passo para a transformação da realidade que está posta, é "[...] aceitar a escola como ela existe. Isso não significa aceitá-la integralmente, com suas distorções, burocratizada, ritualizada, etc. Mas aceitar, sobretudo, a qualidade da população que entrou na escola, que conquistou a escola." Este é o princípio mais importante para a mudança e que não é privilégio de nenhum grande estrategista: compreender o presente para buscar alternativas a curto, médio e longo prazo, visando o futuro.

Essa abordagem da democratização do direito à educação, enquanto conquista quantitativa e ao mesmo tempo qualitativa, possibilita a depreensão de que as questões colocadas em nenhum momento querem dizer que ao novo aluno da escola pública se deva oferecer um pouco menos do que the foi oferecido em termos de conhecimento no passado, mas sim que lhe seja permitido aprender conforme suas características e demandas do presente. Nesse sentido, Beisiegel (2005, p. 121- 122) afirma que:

É possível levar uma educação melhor a essas crianças. Mas o que estou dizendo é o seguinte: quando se diz que foi por causa da expansão do ensino que se chegou a essa situação de crise no ensino, que a expansão do ensino levou a uma deterioração do ensino, na verdade, o que estamos dizendo é o seguinte: é preciso tirar da escola essa população que não rende, porque assim poderíamos voltar a ter a qualidade anterior... Nós estamos democratizando com uma das mãos e tirando com a outra.

Por fim, se faz necessário repensar diante da conquista histórica da educação enquanto direito público subjetivo, que a consolidação de uma educação de qualidade passa necessariamente pela valorização dos sujeitos diretamente envolvidos no processo educativo, quais sejam, alunos e professores. Aos primeiros se deve valorizar suas características e sua legitimidade enquanto ocupantes do espaço escolar e aos segundos, a importância de seu papel na transformação do cenário atual para uma realidade ainda mais democrática. Di Giorgi e Leite (2010) afirmam que não pode haver educação de qualidade sem professor de qualidade. Para os autores, que se pautam na relevância da perspectiva civil democrática como forma de demonstrarem ser possível superar a posição hegemônica da posição produtivista,

[...] professor de qualidade é
profissional bem formado,
motivado, com formação
continuada baseada nos
problemas da prática, realizada
principalmente na própria
escola, que participa ativamente
do projeto político-pedagógico,
que pensa a sua prática. É o
professor intelectual, crítico-
reflexivo. Para que haja tais
professores, é necessário
mudar a sua formação inicial, a
sua formação continuada e,
sobretudo, a relação vertical,
autoritária e desrespeitosa que
caracteriza a forma de atuação
da maioria das instâncias
educacionais centrais com os
professores. (DI GIORGl;
LEITE, 2010, p.320)

Investigar a amplitude das novas políticas públicas educacionais, os novos desafios impostos por elas aos profissionais do magistério e os dados relativos à função docente e trabalho docente na atualidade se torna importante ao passo que Singer (1996), Di Giorgi e Leite (2010) e outros autores, apontam que na questão crucial da qualidade da educação, os defensores da concepção produtivista têm mantido forte hegemonia. É por meio da análise das reformas educacionais em decorrência do Neoliberalismo e crise econômica de 1970, e da reflexão sobre as reestruturações pelas quais passam a carreira dos profissionais do magistério, que se poderá compreender mais crítica e articuladamente o 
atual cenário educacional e suas demandas por qualidade.

Assim, deve-se convir que a escola se insere em um tempo de muitos paradoxos, no qual nunca tantos deixaram de acreditar nela e nunca tantos a desejaram e a procuraram. Ainda, nesse contexto, é fundamental dizer que nunca estiveram convictos da necessidade de sua mudança.

\section{CONSIDERAÇÕES FINAIS}

Feitas as incursões pelos caminhos propostos neste artigo, pretendeu-se apontar que a difundida crise da escola e sua consequente perda de qualidade, não pode ser referendada sem investigações profundas das novas configurações da instituição escolar, das práticas pedagógicas e das transformações sociais que ocorrem ao seu redor.

É necessário reforçar que as mudanças históricas que promoveram a superação do caráter excludente da escola do passado situamse como fatos marcantes para o processo de inclusão das camadas populares, e devem ser vistas como avanços, num sistema educativo determinado, desde sua origem, pela exclusiva preocupação em atender interesses religiosos e elitistas. A inclusão de um novo público aos sistemas de ensino, conforme amplamente discutido ao longo deste estudo, não pode ser responsabilizada pela queda nos níveis de qualidade experimentados no passado, mas refletida à luz de algumas questões básicas: a escola do passado, que se fechou a milhões de brasileiros, embora legitimada como um direito social em várias Constituições Federais pode ser considerada de qualidade? A escola do presente, na qual as mais diferentes culturas se encontram para celebrar as contradições, semelhanças e conflitos da realidade de um país marcado pela exploração, desigualdade social e descasos do poder público, pode ser, agora, a verdadeira culpada por sua crise, por sua perda de qualidade? A quem interessa essa focalização da escola como produtora dos problemas do ensino?

$\mathrm{Na}$ perspectiva de Singer, na qual se apresentou duas posições antagônicas no debate da qualidade da escola pública atual, é possível constatar que as ideias civis democráticas estão claramente sucumbidas pelas tendências produtivistas que, em razão de sua objetividade e ligação com as políticas neoliberais, produzem uma imagem distorcida da escola.

Posto isto, é preciso disseminar que não é correto atribuir o conjunto de desajustes criados nos demais âmbitos da vida social, como problemas oriundos da escola. Esse posicionamento gera novas responsabilidades e a impossibilita cada vez mais de desprender-se das amarras e das constantes críticas que a consideram inadequada, ineficiente e deteriorada. Nesse cenário complexo, somadas às suas funções tradicionais, os sujeitos educativos trabalham duramente para conseguir assegurar a inclusão das novas classes sociais, estabilizá-las com vistas à promoção do ensino formal e efetuar todas as demais etapas de socialização que não foram providas nem pela família e tampouco pelo Estado.

A escola do presente, portanto, pode ser resumida numa instituição multifacetada e multifuncional, ao passo que assume agora, e por isso está em crise, a busca por soluções a problemas sociais crônicos, resultado da exclusão social consentida pelo Estado ao longo dos séculos. E convém assinalar que, "inflada" rapidamente pela democratização do acesso ao ensino, não conseguiu refletir e assumir um novo papel frente às demandas de seu novo público, o que agrava ainda mais esse quadro.

Conforme já abordado, a busca por novos caminhos para a superação da crise da escola e melhoria de sua qualidade depende da valorização de seus sujeitos educativos, em 
especial do aluno e do professor, pois o problema da crise esbarra em um ponto muito bem tratado por Barroso (2008, p. 52), ao lembrar que "A escola não faz sentido fora de projetos sociais. Se faltam estes, a escola fica vazia de sentido, fica em crise. Não nos faltam projetos para as escolas. Faltam-nos projetos para a sociedade".

\section{REFERÊNCIAS}

BARROSO, G. Crise da escola ou na escola? Uma análise da crise de sentido dos sistemas públicos de escolarização obrigatória. Rev. Port. de Educação, v.21, n.1, p.33-58, 2008.

BEISIEGEL, C. R. A qualidade do ensino na escola pública. Brasília: Líber Livro, 2005.

BRASIL. Lei n. 9.394, de 20 de dezembro de 1996. Estabelece as Diretrizes e Bases da Educação Nacional. Disponível em: <http://www.planalto.gov.br/ccivil/LEIS/L8069.htm >. Acesso em: 15 jun. 2011.

CARDOSO, T. F. L. As aulas régias no Brasil. In: STEPHANOU, M.; BASTOS, M. H. C. (orgs.). Histórias e memórias da educação no Brasil: séculos XVI-XVIII. Petrópolis, RJ: Vozes, 2004. v.1, p. 179-191.

CONTRERAS, J. A autonomia de professores. São Paulo. Cortez, 2002.

CURY, C. R. J. A educação como desafio na ordem jurídica. In: LOPES, E. M. T.; FILHO, L. M. F.; VEIGA, C. G. 500 anos de educação no Brasil. 3. ed. São Paulo: Autêntica, 2003. p. 567584

. Estado e políticas de $\overline{\text { financiamento }}$ em educação. Educação \& Sociedade, v. 28, n. 100, p. 831-855, out. 2007.

DAVOK, D. F. Qualidade em Educação. Avaliação. Campinas, v. 12, n. 3, p. 505-513, set. 2007.

DI GIORGI, C. A. G.; LEITE, Y. U. F. A qualidade da escola pública, na perspectiva democrática e popular. Série Estudos - Periódico do Mestrado em Educação da UCDB, Campo Grande, n. 30, p. 305-323. jul./dez. 2010.

DOURADO, L. F.; OLIVEIRA, J. F. A qualidade da educação: perspectivas e desafios. Cadernos do Cedes - Centro de Estudos Educação e Sociedade, Campinas, v. 29, n. 78, p. 201-215, maio/ago., 2009.
FARIA FILHO, L. M.; VIDAL, D. G. Os tempos e os espaços escolares no processo de institucionalização da escola primária no Brasil. 500 Anos de Educação Escolar. Revista Brasileira de Educação, n. 14 Número Especial. maio./ ago. p. 19-34, 2000.

HAIDAR, M. L. M.; TANURI, L. M. A Educação Básica no Brasil: dos primórdios até a primeira Lei de Diretrizes e Bases. In: Estrutura e Funcionamento da Educação Básica. São Paulo: Pioneira, 1998. p. 59 - 101.

HORTA, J. S. B. Direito à educação e obrigatoriedade escolar. Fundação Carlos Chagas. Cadernos de Pesquisa, São Paulo, n. 104, p. 5 - 34, jul., 1998.

MACHADO, N. J. Qualidade da educação: cinco lembretes e uma lembrança. Estudos Avançados, São Paulo,v. 21,n. 61,dez. .2007.

OLIVEIRA, C. et al. A municipalização do ensino brasileiro. In: Municipalização do ensino no Brasil. Belo Horizonte: Autêntica, 1999. p. 11-36.

OLIVEIRA. R. P.de; ARAÚJO. G.C. de. Qualidade do ensino: uma nova dimensão da luta pelo direito à educação. Revista Brasileira de Educação, Rio de Janeiro, n.28, p.5-23, jan./abr. 2005.

PAIVA, V. P. Educação popular e educação de adultos. São Paulo: Loyola, 1987.

PAZ, F. M. da. O Índice de Desenvolvimento da Educação Básica (IDEB): um estudo do município de Santa Fé do Sul/SP. 2011, 189 f. Dissertação (Mestrado em Educação) Faculdade de Filosofia e Ciências - UNESP Univ. Estadual Paulista Marília, Marília.

PAZ et al. Centenário de Birigui: educação. Folha da Região, Araçatuba, Fascículo 13, 2011.

SINGER, P. Poder, política e educação. Revista Brasileira de Educação: São Paulo: ANPED, 1996.

SCHWARTZMAN, S.; DURHAM, E. R; GOLDEMBERG, J. (1993). A Educação no Brasil em uma perspectiva de transformação. Trabalho realizado para o Projeto sobre Educação na América Latina do Diálogo Interamericano. São Paulo, junho de 1993. Disponível em: <http://www.schwartzman.org.br/simon/transform. htm>. Acesso em: 30 dez. 2011.

SOUZA, S. M. Z. L. Avaliação do rendimento escolar como instrumento de gestão educacional. In: OLIVEIRA, D. A. Gestão democrática da 
educação: desafios contemporâneos. 3. ed. Petrópolis: Vozes, 1997. p. 264-283

TANURI, L. M. A administração do ensino no Brasil: $\quad$ centralização $x$ descentralização: Didática, São Paulo, v. 17, p. 5-21, 1981.

TEDESCO, J. C. O novo pacto educativo: educação, competitividade e cidadania na sociedade moderna. São Paulo: Ática, 1998.

VIEIRA, S. L.; FARIAS, I. M. S. de. Política Educacional no Brasil. Introdução Histórica. Brasília: Líber Livro, 2007. 